\title{
Afterslip distribution following the 2003 Tokachi-oki earthquake: An estimation based on the Green's functions for an inhomogeneous elastic space with subsurface structure
}

\author{
Kachishige Sato ${ }^{1}$, Toshitaka Baba ${ }^{2}$, Takane Hori ${ }^{3}$, Mamoru Hyodo ${ }^{3}$, and Yoshiyuki Kaneda ${ }^{2}$ \\ ${ }^{1}$ Department of Astronomy and Earth Sciences, Faculty of Education, Tokyo Gakugei University, \\ Nukuikita-machi 4-1-1, Koganei, Tokyo 184-8501, Japan \\ ${ }^{2}$ Department of Oceanfloor Network System Development for Earthquakes and Tsunamis, \\ Japan Agency for Marine-Earth Science and Technology, \\ Natsushima-cho 2-15, Yokosuka 237-0061, Japan \\ ${ }^{3}$ Institute for Research on Earth Evolution, Japan Agency for Marine-Earth Science and Technology, \\ Showa-machi 3173-25, Kanazawa-ku, Yokohama 236-0001, Japan
}

(Received July 9, 2010; Revised November 17, 2010; Accepted November 18, 2010; Online published February 3, 2011)

\begin{abstract}
We derive the 1-yr afterslip distribution following the 2003 Tokachi-oki (Hokkaido, northeastern Japan) earthquake $\left(M_{\mathrm{W}} 8.0\right)$ by inverting geodetic data, i.e., horizontal and vertical displacements, at 142 land stations of the Global Positioning System (GPS) in Hokkaido and northernmost Tohoku districts, together with vertical displacements at two offshore stations of pressure gauge (PG) off the Pacific coast of Hokkaido. We use the Green's functions (GFs), calculated with a finite element method, for an inhomogeneous elastic (IE) model incorporating subsurface structure. Obtained results show a striking feature of the distribution pattern of significant afterslip, namely, a U-shaped afterslip zone encircling the co-seismic rupture zone of the 2003 event. Amounts of the 1 -yr afterslip reach up to $0.9 \mathrm{~m}$, and total seismic moments released from all afterslip zones are of the order of $10^{21} \mathrm{~N} \mathrm{~m}$, corresponding to an earthquake of $M_{\mathrm{W}}$ 8.0. For comparison, we also estimate the 1-yr afterslips based on GFs for the homogeneous elastic (HE) model to find that the total seismic moment with GFs for the IE model is larger than that with GFs for the HE model by $33 \%$ (when the most probable values are compared) if we assume a rigidity of $40 \mathrm{GPa}$. This result implies that inhomogeneities due to subsurface structure have an important role in geodetic inversions.
\end{abstract}

Key words: 2003 Tokachi-oki earthquake, afterslip, geodetic inversion, Green's function, inhomogeneous elastic space, finite element method.

\section{Introduction}

Since an epoch-making discovery of afterslip (or post-seismic slip) following the 1994 Sanriku-haruka-oki (Tohoku district, northeastern Japan) earthquake $\left(M_{\mathrm{W}} 7.8\right)$ by Heki et al. (1997), the same phenomena have been reported in several studies (e.g., Hirose et al., 1999; Nishimura et al., 2000; Bürgmann et al., 2001; Yagi et al., 2001). Such afterslips have quite a significant role in discussing the deficit of slip amounts after the occurrence of interplate earthquakes, i.e., imbalance between plate convergence rate and amount of co-seismic slip, or furthermore in discussing the recurrence interval or size of the next interplate earthquake. Hence, it is very important to estimate afterslips following such interplate earthquakes as precisely as possible.

The afterslip distribution following the 2003 Tokachioki (Hokkaido, northeastern Japan) earthquake $\left(M_{\mathrm{W}} 8.0\right)$,

Copyright (C) The Society of Geomagnetism and Earth, Planetary and Space Sciences (SGEPSS); The Seismological Society of Japan; The Volcanological Society of Japan; The Geodetic Society of Japan; The Japanese Society for Planetary Sciences; TERRAPUB.

doi:10.5047/eps.2010.11.007 which was the largest interplate earthquake in Japan in the last decade, has been estimated by several authors by inverting geodetic data, i.e., displacements on the ground surface. For example, Miyazaki et al. (2004), Miura et al. (2004), and Ozawa et al. (2004) deduced it from displacement data at many sites in the Hokkaido and northern Tohoku districts of a dense Global Positioning System (GPS) network GEONET (GPS Earth Observation Network; e.g., Miyazaki et al., 1997) operated by the Geospatial Information Authority (GSI) of Japan. Baba et al. (2006) also obtained afterslip distribution by inverting displacement data at many GEONET sites on land with additional vertical displacements at two offshore ocean-bottom pressure gauge (PG) stations operated by the Japan Agency for MarineEarth Science and Technology (JAMSTEC) (e.g., Hirata et al., 2002). In these geodetic inversions, all authors used the Green's functions (GFs, i.e., theoretical ground surface displacements due to unit dislocations on subsurface faults) calculated for a homogeneous elastic half-space or for horizontally layered elastic media.

However, using the GFs calculated under such rather simplified elastic conditions seems to be misleading in the esti- 
mation of afterslip distribution, since the subsurface structure of any region, especially that in and around Japan, is more or less inhomogeneous, and such inhomogeneity should affect, to a certain extent, the surface displacements. In fact, performing some numerical 3D finite element calculations with a grid model for the Hokkaido and Tohoku districts, Sato et al. (2007) clarified that a very large discrepancy in the surface displacements existed between the cases of homogeneous and inhomogeneous elastic subsurface models. The discrepancies they found were more than $20 \%$ and even as large as $\sim 40 \%$ in some cases. On the other hand, the surface displacement data usually employed in geodetic inversions are those obtained with GPS having quite high precision, varing a few $\mathrm{mm}$ (for horizontal displacements) to several $\mathrm{mm}$ (for vertical displacements) (e.g., Nishimura et al., 2004). Hence, such quite large discrepancies strongly suggest that, for more precise and reliable geodetic inversions of afterslip distribution, the surface displacement calculated for an inhomogeneous elastic medium with realistic subsurface structure, unlike the usual cases so far, should be used as the GFs.

In this paper, we perform some inversions by using the GFs calculated for inhomogeneous elastic media, incorporating a realistic subsurface structure to estimate the afterslip distribution following the 2003 Tokachi-oki earthquake. We also perform an inversion with the GFs calculated for homogeneous elastic media to compare the obtained afterslip distribution with those obtained from GFs for inhomogeneous elastic media.

\section{Method of Geodetic Inversions}

The 2003 Tokachi-oki earthquake was an interplate earthquake that occurred on the plate interface between the subducted oceanic plate, namely, the Pacific plate, and the landside North American (or Okhotsk) plate. Hence, we naturally assume that the afterslip following the earthquake also took place on the plate interface between these two plates. The configuration of the boundary between the two plates in and around the epicentral region of the 2003 event has been proposed by several authors, mainly based on seismological studies (e.g., Hasegawa et al., 1983; Suzuki et al., 1983; Miyamachi et al., 1994; Katsumata et al., 2003). Among them, we adopt the one newly determined by Katsumata $e t$ al. (2003), which based on the hypocentral distribution of local earthquakes.

In order to estimate the distribution of afterslip, the plate interface in and around the co-seismic slip zone of the 2003 event beneath the Pacific coast of Hokkaido is divided into many cell-like rectangular subfaults (total number of subfaults is $I \times J$, where $I$ and $J$ are the numbers of subfaults within each row and column of the subfault array). Fixing the azimuth of the afterslip vector (i.e., the direction of horizontal component of afterslip vector), we estimate the slip amount on each subfault (note that only the azimuth of afterslip vector is fixed and the direction of afterslip vector on each subfault plane is adjusted according to its geometry, namely, the strike and dip angle of the subfault plane). The azimuth of afterslip vector on each subfault is based on that of the co-seismic slip vector of the 2003 event determined by Yamanaka and Kikuchi (2003). This azimuth of afterslip vector is assumed to be adequate for all subfaults not only inside the co-seismic rupture zone but also outside.

In the inversion, we impose the same constraint as that adopted by Baba et al. (2006), i.e., a smoothness constraint, on the slip distribution on each subfault as follows:

$$
0=x_{i-1, j}+x_{i+1, j}+x_{i, j-1}+x_{i, j+1}-4 x_{i, j},
$$

where $x_{i, j}$ is the slip amount on the $(i, j)$-th subfault. Equation (1) can be rewritten in a matrix form as follows:

$$
\mathbf{0}=\mathbf{S x}
$$

where $\mathbf{S}$ is a matrix representing the smoothness constraint, whose elements can be calculated based on Eq. (1), and $\mathbf{x}$ is a vector of slip amounts on subfaults. The smoothness constraint represented by Eq. (2) can then be combined with a usual observational equation to form a modified one as follows:

$$
\left(\begin{array}{c}
\mathbf{d} \\
\mathbf{0}
\end{array}\right)=\left(\begin{array}{c}
\mathbf{G} \\
\alpha \mathbf{S}
\end{array}\right) \mathbf{x}
$$

where $\mathbf{d}$ is a vector of observed surface displacements, and $\alpha$ represents a smoothness parameter weighting the smoothness matrix $\mathbf{S}$. G in Eq. (3) is a matrix whose element $G_{m, n}$ is the so-called GF describing the expected surface displacement at the $m$-th observation point caused by a unit dislocation on the $n$-th subfault $(n=I \times(j-1)+i$ for the $(i, j)$-th subfault). The method of calculation of the GFs will be described in the next section. First, assuming a certain value for the smoothness parameter $\alpha$, we solve Eq. (3) with an ordinary least squares method. Next, we calculate the so-called Akaike's Bayesian Information Criterion (ABIC) (Akaike, 1980) based on Yabuki and Matsu'ura (1992) using the obtained model parameters and the assumed $\alpha$. These processes are repeated to find the most appropriate smoothness parameter $\alpha$ which gives the minimum ABIC. Finally, using the smoothness parameter $\alpha$ obtained we solve Eq. (3) with a non-negative least squares (NNLS) algorithm (e.g., Lawson and Hanson, 1974), together with a constraint for the slip at the lateral edges of the afterslip zone to be zero, to ensure stability of solution. Model error is also estimated with a boot strapping method (e.g., Tichelaar and Ruff, 1989).

\section{Calculation of GFs}

As mentioned earlier, GFs, i.e., the expected surface displacement at each observation point caused by a unit dislocation on each subfault, have been usually calculated with an assumption of a homogeneous or simply layered elastic half-space (e.g., Miura et al., 2004; Miyazaki et al., 2004; Ozawa et al., 2004; Baba et al., 2006). However, such a simplified assumption seems inappropriate, especially for the region in and around Japan where the subsurface structure is very complicated. Hence, in order to incorporate the inhomogeneity due to such complication of subsurface structure, we adopt a 3D finite element technique in the calculation of GFs. For the calculation, we use the GeoFEM, a parallelized finite element code, developed at the Research Organization for Information Science and Technology (RIST) (e.g., Iizuka et al., 2002; Hyodo and Hirahara, 2004). 


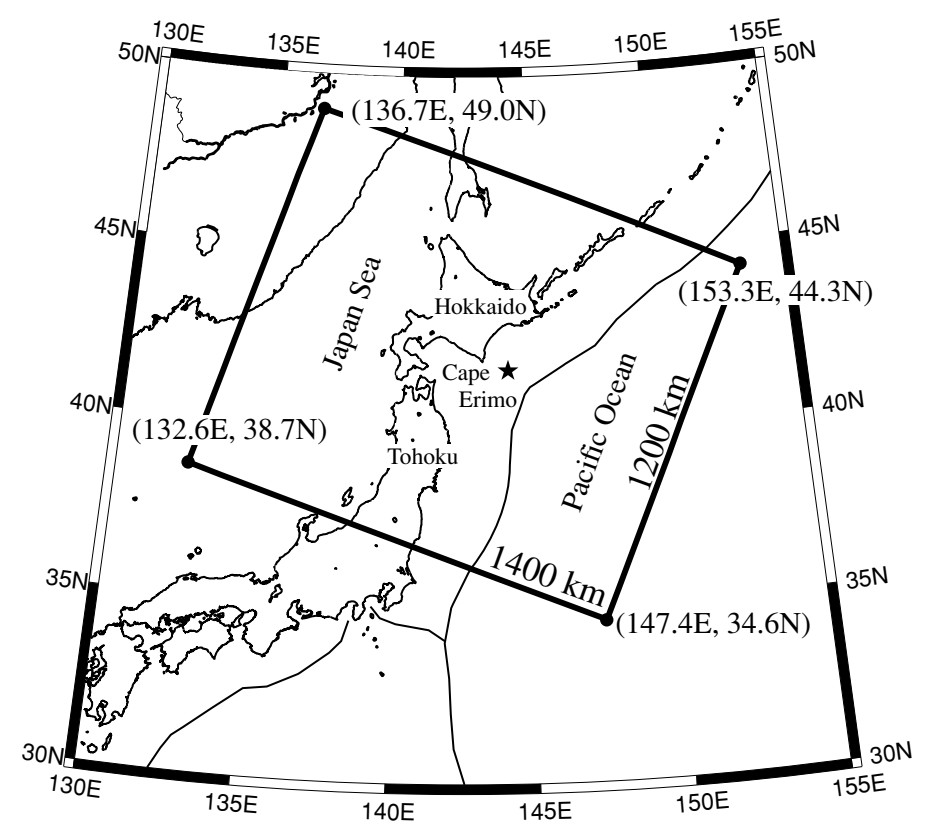

Fig. 1. Map showing the region modeled with a 3D finite element method for the calculation of the GFs in this study. A rectangular region (indicated by thick lines) with a dimension of $1400 \mathrm{~km}$ (in the ESE direction) $\times 1200 \mathrm{~km}$ (in the NNE direction) is modeled. The star indicates the approximate epicenter of the 2003 Tokachi-oki earthquake.

\subsection{Subsurface structure and finite element grid}

The model space and assumed subsurface structure for the finite element calculation are the same as those in Sato el al. (2007), so that we describe them briefly. The rectangle in Fig. 1 shows the model region, including the Hokkaido and Tohoku districts, northeastern Japan. The model space has a dimension of $1400 \mathrm{~km}$ (in the ESE direction) $x$ $1200 \mathrm{~km}$ (in the NNE direction) $\times 200 \mathrm{~km}($ depth$)$. Since the curvature of the Earth's surface is not taken into account, the model surface is treated as a flat plane. The assigned subsurface structure is shown in Fig. 2(a) which consists of four subregions, i.e., upper crust (UC), lower crust (LC), upper mantle (UM), and Pacific plate (PL). This subsurface structural model is based on the iso-depth contours of the Conrad and Moho planes given by Zhao et al. $(1992,1994)$ and of the upper plane of the Pacific plate drawn by Katsumata et al. (2003, beneath Hokkaido area) and Hagiwara (1986, beneath Tohoku area).

We build a 3D finite element grid as shown in Fig. 2(b) by dividing the model space into many hexahedron elements with the CHIKAKU modeling system, consisting of CHIKAKU-DB and CHIKAKU-CAD developed at the RIKEN (e.g., Kanai et al., 1999, 2000, 2001) and CHIKAKU-MESH developed at the Japan Atomic Energy Agency (JAEA) (e.g., Miyamura et al., 2004; Oishi et al., 2004). In order to obtain the GFs as precisely as possible, the grid used in the present study is much finer than that used in the previous study (Sato el al., 2007); the numbers of nodes and elements in the grid are 1,155,375 and $1,121,952$, respectively, which are almost eightfold larger than those of the grid used in the previous study. A typical element near the surface in the central portion of the model has a size of $\sim 8 \mathrm{~km}$ (in horizontal direction) $\times 1 \mathrm{~km}$ (in depth direction). Examples of the vertical cross-sectional views (in the ESE direction) of subsurface structure and fi- nite element grid are shown in Fig. 3(a) and (b), respectively, which correspond to those along the lines A-B in Fig. 2(a) and (b).

\subsection{Material properties}

The elastic material parameters, i.e., the Young's modulus and Poisson's ratio, assigned to UC, LC, UM, and PL are summarized in Table 1. In Table 1, the $P$ - and $S$-wave velocities and densities for UC, LC, and UM used to derive the Young's modulus and Poisson's ratio are also listed. These $P$ - and $S$-wave velocities are based on the seismological tomography by Nakajima et al. (2001), and densities are taken from Dambara and Tomoda (1969). The Young's modulus and Poisson's ratio of PL are adopted from Liu (1980) and Suito and Hirahara (1999), respectively.

In order to compare the afterslip distribution following the 2003 event obtained for an inhomogeneous subsurface structure with that for the homogeneous case, we also calculated the GFs for homogeneous elastic media, with the Young's modulus and Poisson's ratio presented in parentheses in Table 1 (i.e., $100 \mathrm{GPa}$ and 0.25 , respectively, as typical values). Hereafter, we denote these two material models as the inhomogeneous elastic (IE) model and homogeneous elastic (HE) model, respectively.

\section{Data}

The data we use here to derive the 1-yr afterslip following the 2003 Tokachi-oki earthquake are the same as those employed in Baba et al. (2006). The data consist of two types; one is site displacement data obtained at continuous GPS stations and the other is offshore vertical movement data acquired with PG. These GPS and PG data are plotted in Fig. 4(a) and (b). The GPS data are horizontal and vertical displacements at 142 stations in the Hokkaido and northernmost Tohoku districts, which are the relative ones at the stations with respect to a reference station denoted by "R" 
(a)

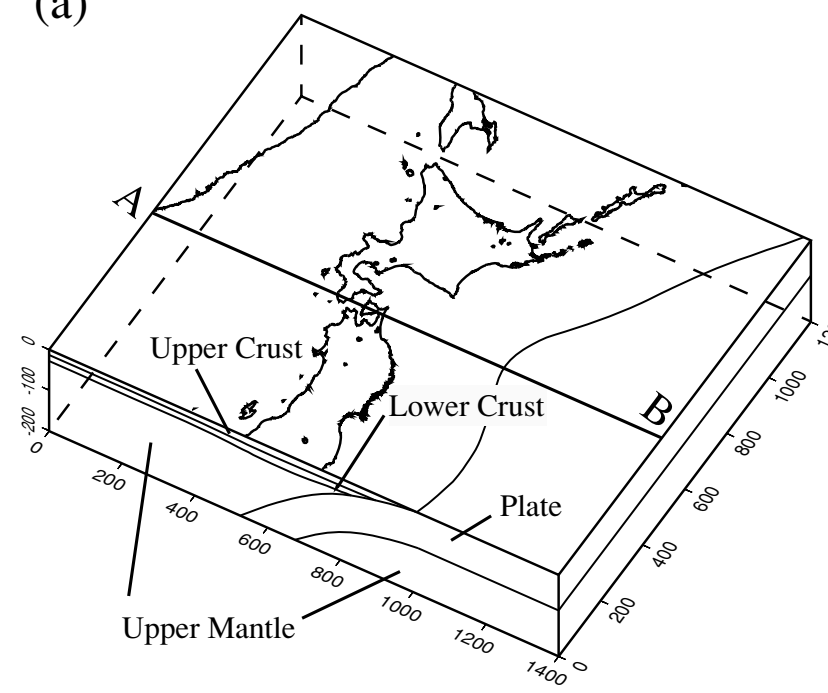

(b)

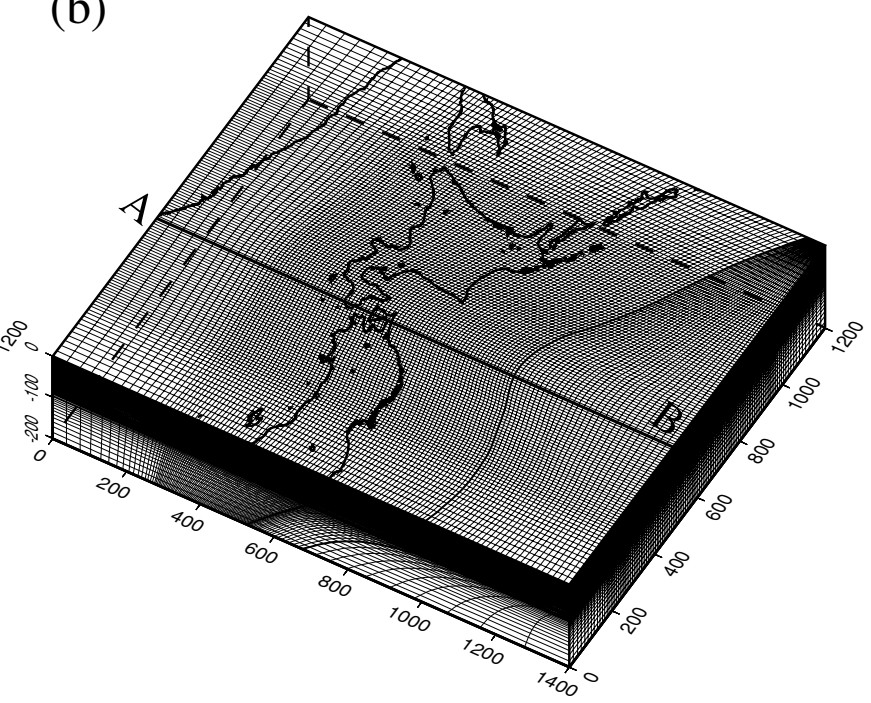

Fig. 2. (a) Outline and assumed subsurface structure of the 3D model consisting of four subregions, i.e., upper crust, lower crust, upper mantle and plate. (b) 3D finite element grid with 1,155,375 nodes and 1,121,952 elements. Cross-sectional views along the thick lines A-B are shown in Fig. 3.
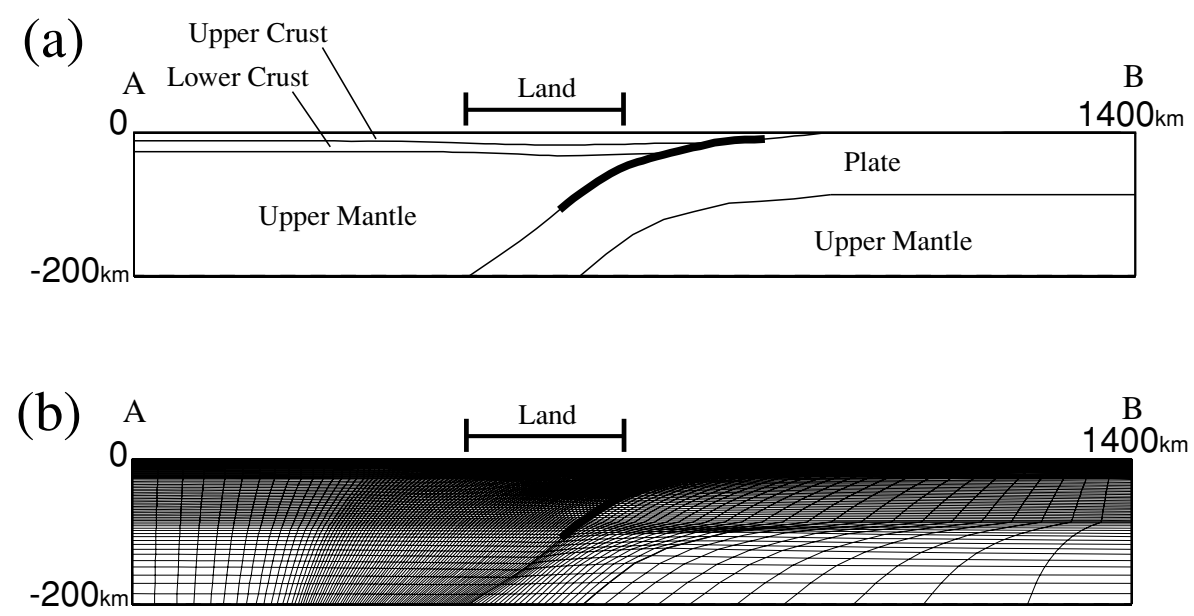

Fig. 3. Examples of vertical cross-sectional views (in the ESE direction) for (a) subsurface structure and (b) finite element grid. These cross-sections are along the lines A-B in Fig. 2(a) and (b), and the thick lines on the Pacific plate interface denote the area where afterslips are assumed to occur. Approximate position of typical land area is also indicated in each figure.

Table 1. Elastic material parameters in each region.

\begin{tabular}{cccccc}
\hline Region & $V_{p}^{\mathrm{a}}(\mathrm{km} / \mathrm{s})$ & $V_{s}^{\mathrm{b}}(\mathrm{km} / \mathrm{s})$ & $\rho^{\mathrm{c}}\left(\times 10^{3} \mathrm{~kg} / \mathrm{m}^{3}\right)$ & $E^{\mathrm{d} *}(\mathrm{GPa})$ & $\nu^{\mathrm{e} *}$ \\
\hline Upper Crust & 5.664 & 3.300 & 2.67 & $72.3(100)$ & $0.243(0.250)$ \\
Lower Crust & 6.570 & 3.730 & 3.00 & $105(100)$ & $0.263(0.250)$ \\
Upper Mantle & 8.270 & 4.535 & 3.32 & $176(100)$ & $0.285(0.250)$ \\
Plate & - & - & - & $95.4(100)$ & $0.258(0.250)$ \\
\hline
\end{tabular}

${ }^{\mathrm{a}} P$ - and ${ }^{\mathrm{b}} S$-wave velocities and ${ }^{\mathrm{c}}$ densities for Upper Crust, Lower Crust and Upper Mantle are from Nakajima et al. (2001) and from Dambara and Tomoda (1969), and d'Young's modulus and ePoisson's ratio for Plate from Liu (1980) and from Suito and Hirahara (1999), respectively. *Young's modulus and Poisson's ratio in parenthesis are those for the homogeneous elastic model.

in Fig. 4(a) and (b) (see Baba et al., 2006). In contrast, the PG data are absolute vertical displacements at two stations located far off the Pacific coast of Hokkaido operated by JAMSTEC. These absolute PG displacements are estimated after subtracting such components as the instrumental drift, ocean tides and thermal noises from the raw data, and they are considered to have observation errors of the order of
$1 \mathrm{~cm}$ (see Hirata et al. (2002) and Baba et al. (2006) for detailed description on data reduction). All of these horizontal and vertical displacements at GPS and PG stations are those accumulated from 1 day to 1 year after the mainshock of the 2003 event, so that the afterslip distribution obtained here by the inversion of these data corresponds to that accumulated within this period (i.e., almost 1-yr afterslip distri- 
(a) horizontal components

(b) vertical components

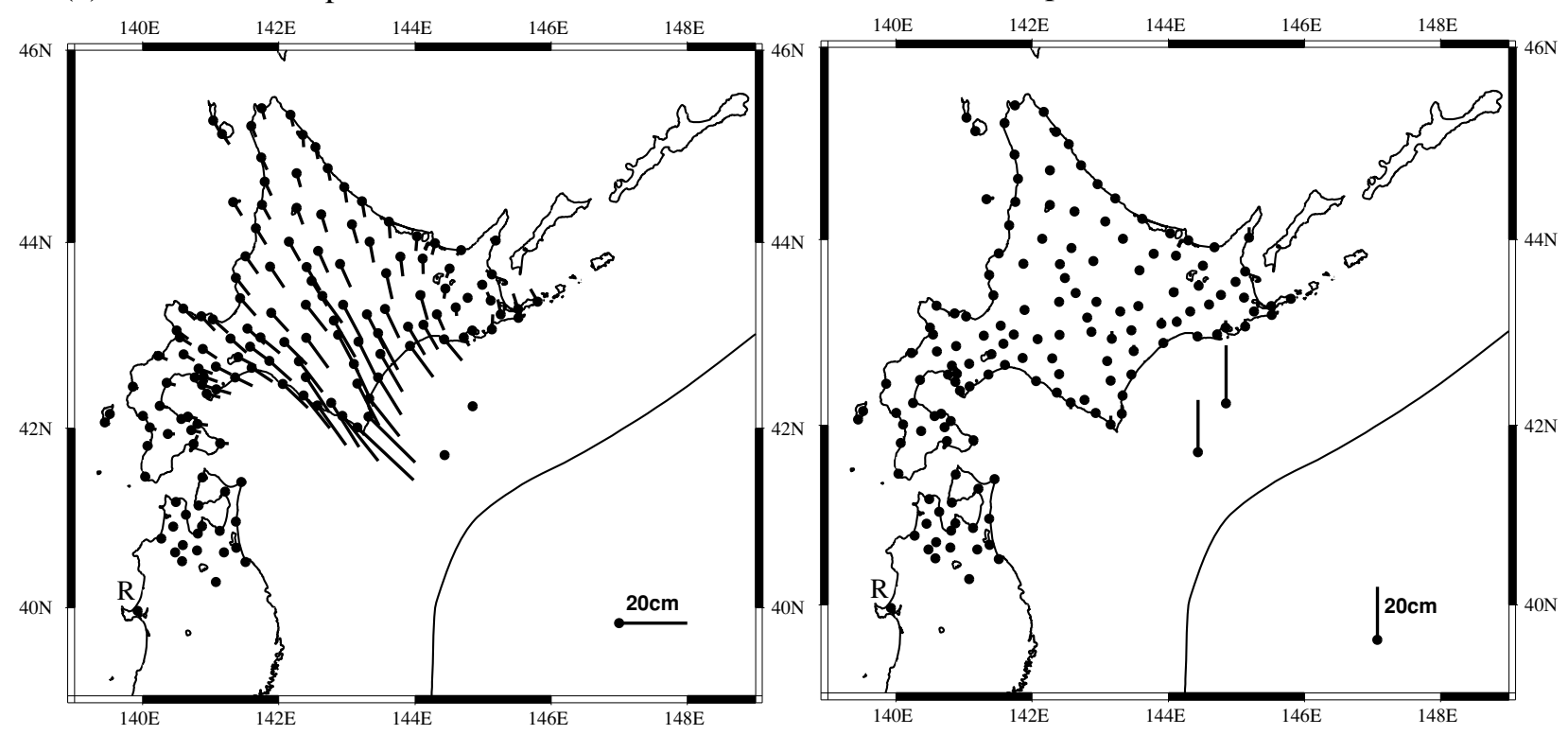

Fig. 4. Displacement data used for inversion of the 1-yr afterslip distribution following the 2003 Tokachi-oki earthquake. (a) Horizontal components and (b) vertical components. Land data are those for 142 GPS stations constituting the GEONET by GSI, and offshore data are those for two PG stations by JAMSTEC. The station denoted by "R" near the southwest corner in both figures indicates the reference point for the displacements.

bution). From the figures, it is found that the directions of horizontal GPS displacements are almost uniform and toward the southeast (i.e., toward the epicenter of the 2003 event). These horizontal displacements take the maximum value of $\sim 22 \mathrm{~cm}$ at a station near Cape Erimo, Pacific coast of Hokkaido, and decay gradually toward the inland area. In the southwestern portion of the Hokkaido and northernmost Tohoku area, there is no considerable horizontal displacement. Significant vertical displacements (uplift of $\sim 20 \mathrm{~cm}$ ) can be recognized only at the two offshore PG stations.

It should be noted that vertical displacement data obtained with GPS and PG have relatively larger observation errors than horizontal ones. However, if the data are weighted in inversions based on their errors, the retrieved afterslip distributions strongly depend only on the horizontal data, and the residuals of vertical data are larger than those of horizontal ones (this is because of two reasons: (1) amount of vertical data is almost half of that of the horizontal data, (2) the vertical displacements are generally smaller than horizontal ones). This means that the vertical data have to be adequately treated in inversions. Hence, in the present study, all data are assigned an equal weight so that the afterslip distribution can be appropriately determined.

Also note that the displacement at each station shown in Fig. 4(a) and (b) may be a mixture caused by two effects on the plate interface, namely, the effect of afterslip to be estimated and that of drag (or the so-called back slip) on other portions of the plate interface due to stationary plate subduction. However, since the latter is considered to be much smaller than the former in the time span within 1 year after the 2003 event, we simply assume here that all displacements used for the inversions are those caused by only the former, i.e., afterslip. Although such simplification may introduce some bias into the estimated afterslip distributions, they can be still considered to preserve the essential feature of them.

\section{Results}

\subsection{Checkerboard resolution test}

In order to assess the resolving power of the inversion scheme described in the previous section, before inverting the actual dataset we perform a checkerboard resolution test using synthetic data calculated from an artificial slip distribution (i.e., a "checkerboard" pattern). The assumed "checkerboard" pattern consists of slips of $0.9 \mathrm{~m}$ and $0 \mathrm{~m}$ on alternating subfaults, as shown in Fig. 5(a). First, theoretical crustal displacements at all stations shown in Fig. 4(a) and (b) due to such slip distribution are calculated. Then, these theoretical values of displacements are disturbed by adding Gaussian random noise to create a synthetic dataset. Considering previous studies by, for example, Nishimura $e t$ al. (2004), the standard deviations of added Gaussian random noise are set to $1 \mathrm{~mm}$ and $3 \mathrm{~mm}$, respectively, for horizontal and vertical displacement data.

Such synthesized data with Gaussian random noise are treated as observed ones and inverted to reproduce the "checkerboard" pattern of assumed slip distribution. The retrieved slip distribution is shown in Fig. 5(b), which should be compared with the assumed slip distribution shown in Fig. 5(a). The assumed slip pattern is found to be fairly well reproduced beneath the land area and the area within about $80-100 \mathrm{~km}$ off the coastline, although it has not been adequately reproduced, in general, in the offshore area far off the coastline. From this resolution test, it can be said that the distribution of the data to be used for inversion in the present study has a fairly good resolving power for most of the area where the afterslip might occur, except for the offshore area far off the coastline, so that the afterslip distributions obtained from these data are considered to be mostly reliable. 
(a) assumed checkerboard pattern

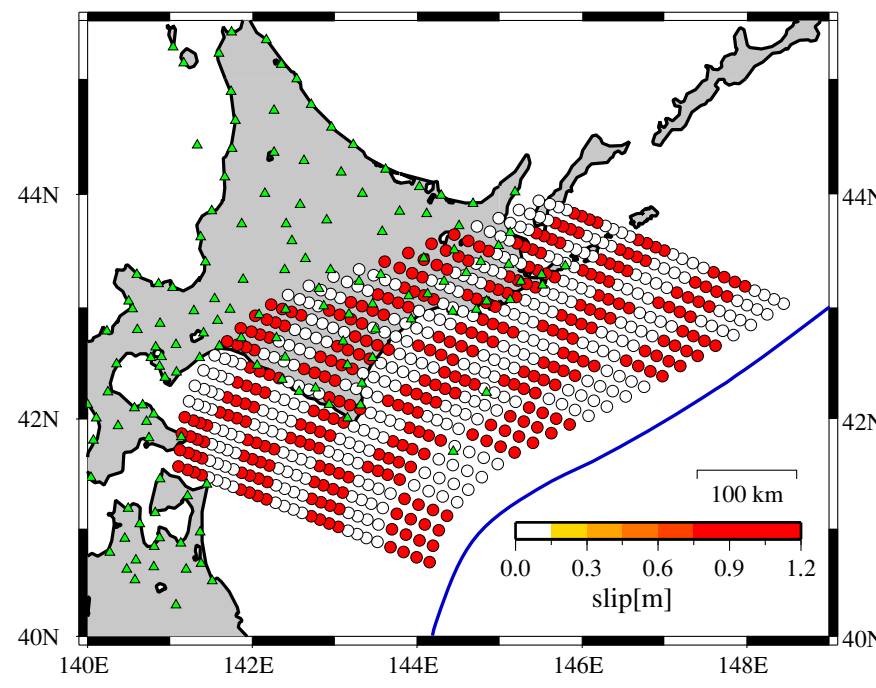

(b) reproduced checkerboard pattern

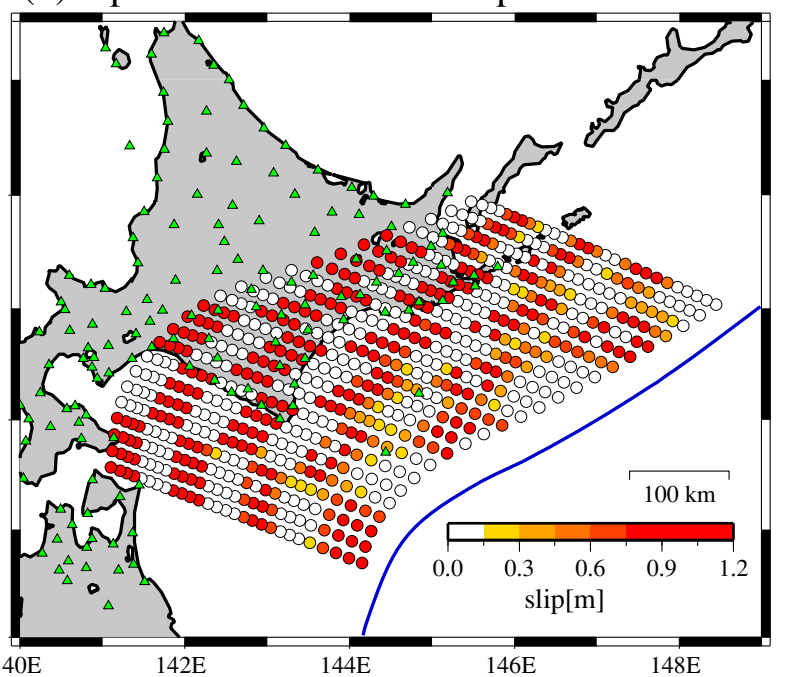

Fig. 5. Result of a checkerboard resolution test. (a) Assumed checkerboard pattern of slip distribution on the plate boundary, and (b) reproduced slip distribution from horizontal and vertical displacement data at 142 land GPS stations and vertical displacement data at two offshore PG stations. Green triangles indicate the land GPS and offshore PG stations used for the resolution test. Approximate trench axis is also shown with a blue line.

\subsection{One-year afterslip distribution of the 2003 Tokachi-oki earthquake}

Inverted 1-yr afterslip distributions following the 2003 Tokachi-oki earthquake together with their error distributions (1- $\sigma$ standard deviations) are described below.

\subsubsection{Afterslip obtained with GFs for IE model} First, the results with GFs for the IE model are presented. Figure 6(a) and (b) show the obtained 1-yr afterslip and its error distributions. In this case, the most appropriate smoothness parameter $\alpha$ in Eq. (3) is found to be 0.022 based on the minimum ABIC of 435.4.

From the figure, it is found that significant afterslips are retrieved in three zones; the first one is a zone almost linearly running from west to southeast of Cape Erimo, the second is a zone also linearly running out to the offshore of Tokachi area, almost parallel to the first one, and the third is a linear zone located off the Tokachi running almost parallel to the coast. These three zones of significant afterslip thus form an almost U-shaped pattern, with the southwest corner of the "U" clearly extending toward the far offshore (i.e., toward the southeast). Amounts of the afterslips are mostly more than $0.45 \mathrm{~m}$ and even reach up to $0.9 \mathrm{~m}$. The region surrounded by these significant afterslip zones has no afterslip; this is a striking feature of the obtained afterslip distribution. On the other hand, errors of afterslips are mostly less than $0.3 \mathrm{~m}$, gradually increasing with increasing distance from the land area to take the maximum $(\sim 0.75 \mathrm{~m})$ error far off Cape Erimo. Such a pattern of error distribution, which is consistent with the result of the checkerboard resolution test shown in Fig. 5(b), is very natural, since almost all data used for inversion are those on land, and only a few offshore data are available. Note that, although the errors in both areas beneath the Tokachi Plain (north of Cape Erimo) and off the plain are shown with the same color in the figure corresponding to a range between $0.15 \mathrm{~m}$ and $0.3 \mathrm{~m}$, there is some difference between them if examined in detail; the errors in the area beneath the Tokachi Plain are smaller than those in the area off the plain (the formers are less than $0.2 \mathrm{~m}$ while the latters are mostly between $0.2 \mathrm{~m}$ and $0.3 \mathrm{~m}$ ).

5.2.2 Afterslip obtained with GFs for HE model Next, the results with GFs for the HE model will be given. The obtained 1-yr afterslip and its error distributions are shown in Fig. 7(a) and (b). In this case, ABIC takes its minimum value of 399.9, giving the most appropriate smoothness parameter $\alpha$ of 0.017 . In order to verify the afterslip distribution shown in Fig. 7(a), we compare it with the one obtained with the GFs analytically calculated for a homogeneous elastic half-space having the same value of elastic properties as the HE model listed in Table 1. Analytical calculations of GFs were performed using a computer program for triangular dislocations coded by W. Stuart at the United States Geological Survey (personal communication) based on Comninou and Dundurs (1975). The afterslip distribution shown in Fig. 7(a) was found to be consistent with that obtained with thus analytically calculated GFs (root mean square (RMS) discrepancy between them is $0.034 \mathrm{~m}$ ).

The retrieved afterslip distribution pattern is mostly similar to that obtained with GFs for the IE model shown in Fig. 6(a), and amounts of the afterslips are again mostly more than $0.45 \mathrm{~m}$, even reaching up to $0.9 \mathrm{~m}$. However, one remarkable difference between these two cases, i.e., those with GFs for the HE and IE models, should be recognized; the extreme extension of the U-shaped significant afterslip zone in the southwest corner seen in the IE model case disappears in the HE model case. In addition, each region forming the U-shaped afterslip zone seems to be slightly thinner in the case of the HE model than that in the case of the IE model. Error distribution pattern is also similar to that in the IE model case shown in Fig. 6(b); errors of afterslips are again mostly less than $0.3 \mathrm{~m}$ with a maximum error of $\sim 0.45 \mathrm{~m}$ at a region far off Cape Erimo. 
(a) afterslip

\section{(b) error}

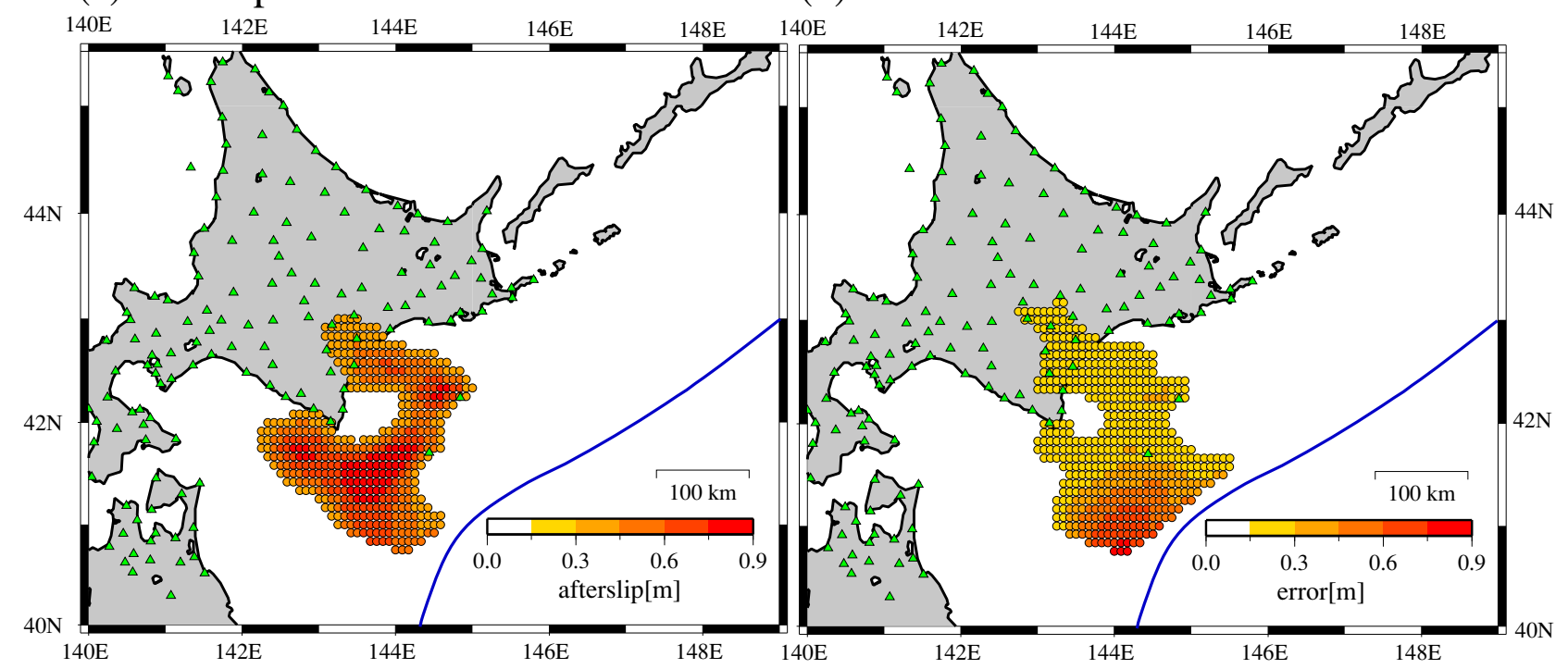

Fig. 6. (a) Distributions of 1-yr afterslips and (b) its 1- $\sigma$ standard errors with GFs for the IE model estimated from horizontal and vertical displacements at 142 land GPS stations and vertical displacements at two offshore PG stations. The 1- $\sigma$ standard error distribution is obtained with a boot strapping method. Note that both distributions of afterslips and 1- $\sigma$ standard errors are shown after optimal Delaunay triangulation and gridding by using the "triangulate" utility included in the Generic Mapping Tools (Wessel and Smith, 1998) so that they are plotted on grid points with an interval of 5 min. Green triangles indicate the land GPS and offshore PG stations whose data are used for inversions. Approximate trench axis is also shown with a blue line.

(a) afterslip

(b) error

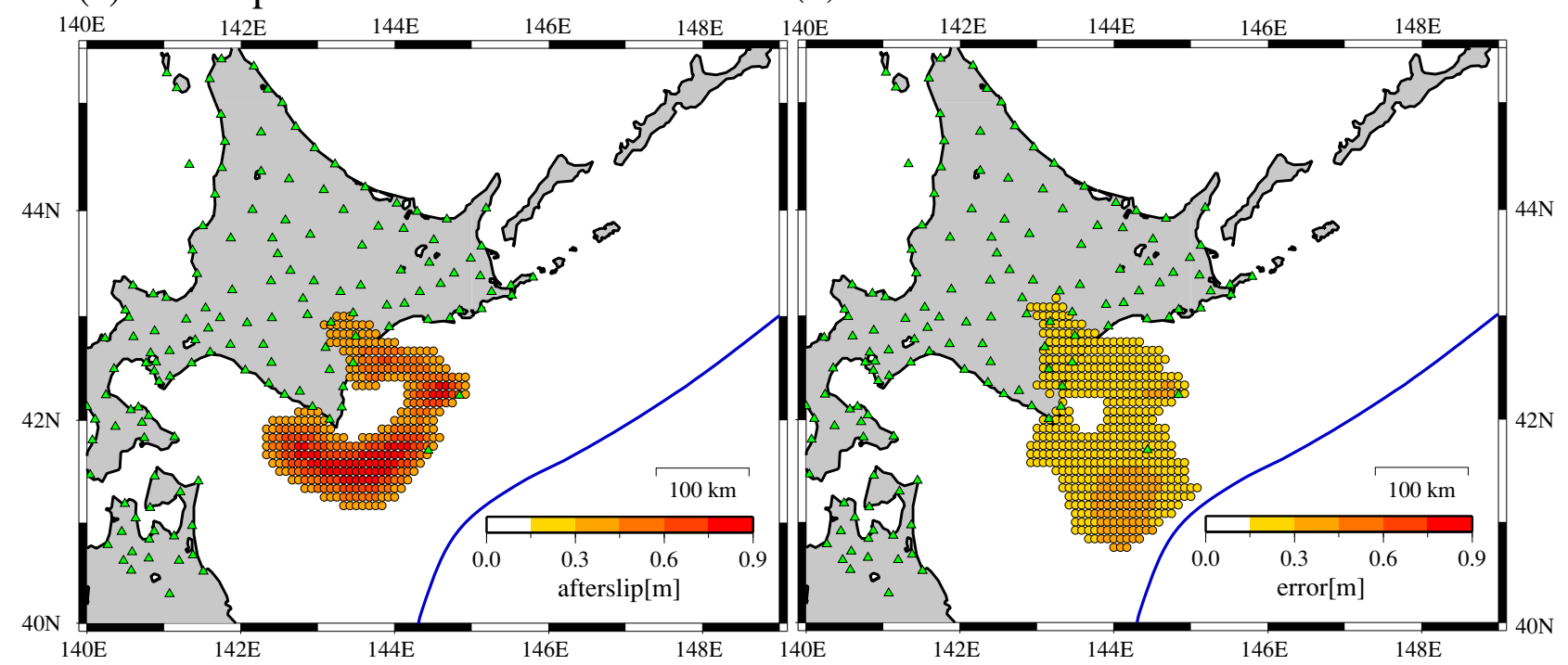

Fig. 7. As in Fig. 6, but with GFs for the HE model.

\section{Discussion}

Here we discuss the 1-yr afterslip distribution following the 2003 Tokachi-oki earthquake obtained in the present study. First, we compare our results with those in other studies. As mentioned earlier, several authors have estimated the afterslip distribution following the 2003 Tokachioki earthquake by using GFs calculated for a uniform and homogeneous elastic half-space or for a horizontally layered elastic media (e.g., Miura et al., 2004; Miyazaki et al., 2004; Ozawa et al., 2004; Baba et al., 2006). Choosing the result obtained by Baba et al. (2006) among these, we compare the afterslip distribution obtained here for the
HE model with their result. The reasons for choosing Baba et al. (2006) to be compared with our results are as follows. First, our observational data used to derive the afterslip distribution are the same as those used by Baba et al. (2006), and second, both studies estimate only the amount of afterslips by fixing the direction of afterslips. Comparing the afterslip distribution shown in Fig. 7(a) with their estimation from the same dataset including the PGs data (i.e., figure 6(b) in Baba et al., 2006), we become aware that these two results are generally very similar to each other. Thus, it can be said that both our inversion and their inversion give almost the same afterslip distribution. However, 


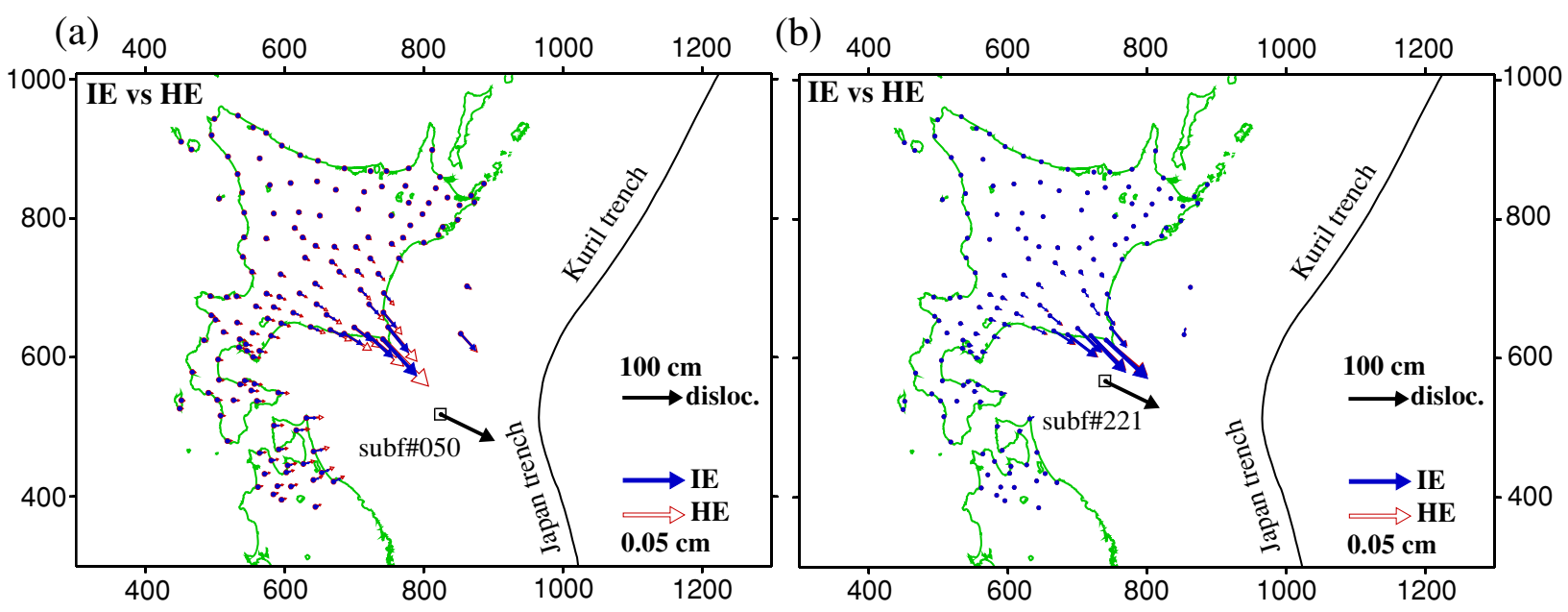

Fig. 8. Comparison of GFs, i.e., surface displacements due to a unit dislocation on a subfault, between the IE and HE models. (a) GFs (horizontal components) against subfault\#050 which is located almost at the center of the area where the afterslip distributions are different between these two models. (b) Same as (a), but against subfault\#221 located in the area where the afterslip distributions for these two models are almost same. Note that the displacement vectors shown in (b) for the IE and HE models at each point are not distinguishable from each other since they are almost identical. Approximate locations of subfault\#050 and subfault\#221 are also indicated with small squares.

a detailed comparison reveals some discrepancy. In our results, the region of larger afterslip can be seen more in the southern area, while in their results this region seems to be located rather in northern portion of afterslip area. This discrepancy between our estimation and their estimation may be based on the assumed geometries of subfaults in these two estimations being slightly different from each other, especially in the southwestern portion of the subfault array, though both of them are based on the plate interface model by Katsumata et al. (2003). In these two estimations, the strike and dip angle of subfaults do not strictly coincide. Baba et al. (2006) fixed the strike to 240 degrees for all subfaults, and only dip angles were adjusted to the shape of the plate interface. On the other hand, in our model, both the strike and dip angle of each subfault were adjusted to the geometry of the plate interface.

Next, as pointed out in the previous section, the most striking feature of afterslip distribution patterns shown in Figs. 6 and 7, respectively, with the GFs for the IE and HE models, is that there is an area of no afterslip almost encircled by U-shaped significant afterslip zones. The area where no afterslip is retrieved approximately coincides with the main co-seismic slip zone of the 2003 event clarified from seismic inversion (e.g., Yagi, 2004). Such a pattern of afterslip distribution following this earthquake was also retrieved by Baba et al. (2006) as mentioned above. This feature of afterslip distribution pattern suggests that the coseismic rupture zone of the large earthquake and its afterslip zone are complementary with each other and has a significant role in investigation of physics of large earthquakes.

Although both of the afterslip distributions obtained with the GFs for the IE and HE models show a U-shaped pattern, there is remarkable difference in the shapes at the southwest corner; an extreme extension of significant afterslip zone, toward the far offshore in the southeast direction, can be recognized in the case of GFs for the IE model, while such an extension disappears in the case of GFs for the HE model. Of course, since the estimation errors of afterslips are rather larger there, it may not be adequate to emphasize this difference too much. However, the fact that such an extension of the significant afterslip zone at the southwest corner can be seen clearly in one case (i.e., IE case) while it can not be seen at all in another case (i.e., HE case), although the errors are similarly larger there in both cases, may suggest that this difference in the afterslip distribution between the IE and HE models reflects more or less the reality. If so, it might be of importance in any discussion of the extent of area where the elastic energy is released as afterslips.

By the way, what is the reason for this difference in afterslip distribution at the southwest corner between the IE and HE models? This difference is considered to be derived from the discrepancy of GFs between these two models. To confirm this, we compare GFs for these two models against subfaults located in this portion. Figure 8(a) illustrates the difference of GFs (horizontal components) between the IE and HE models against one of such subfaults; i.e., subfault\#050, for example, which is just located, as shown in the figure, almost at the center of the extremely extending portion of the U-shaped afterslip distribution. It is obvious that there are significant differences in GFs between the IE and HE models, especially for the stations in and around Cape Erimo where the difference in GFs reaches more than $30 \%$. On the other hand, GFs for the IE and HE models are almost identical to each other against subfaults located in the portion where the afterslip is commonly retrieved for these two models. For example, Fig. 8(b) shows GFs for the IE and HE models against subfault\#221 whose location is indicated in the figure. Although we show in Fig. 8 the comparison of GFs only for horizontal components, the same features as those described here can be noticed for the vertical components of GFs. Thus, the difference in the afterslip distribution between the IE and HE models can be attributed to the discrepancy in GFs between these two models. What then does cause such large discrepancy in GFs against the subfault\#050 between the IE and HE models? 
As seen in the figure, this subfault is located near the JapanKurile trench-trench junction far off Cape Erimo. The area near the junction must be strongly affected by inhomogeneity due to subsurface structure, and thus the GFs against subfaults near the junction, such as subfault\#050, can differ greatly between the IE and HE models. On the other hand, subfault\#221 is far away from the junction, so that the effect of inhomogeneity is not so large there resulting in almost identical GFs between the IE and HE models.

Finally, in order to compare the results of afterslip distribution with GFs for the IE and HE models from another point of view, we calculate the total seismic moments released from all subfaults. In these calculations, a rigidity of $40 \mathrm{GPa}$ is used for all subfaults in the HE model case, while those of 33.5 GPa, 39.7 GPa, and 53.2 GPa are respectively used for the subfaults between UC and PL, between LC and PL, and between UM and PL in the IE model case. These values of rigidity are calculated from the Young's moduli and Poisson's ratios for UC, LC, UM, and PL in each model (in the case of the IE model, the rigidities for subfaults between, for example, UC and PL, are assumed to be the average value of those of UC and PL). Thus, the calculated total seismic moment for the IE model case is (1.06 $\pm 0.60) \times 10^{21} \mathrm{~N} \mathrm{~m}$ (corresponding to an earthquake of $\left.M_{\mathrm{W}} 8.0\right)$, while that for the HE model case is $(0.80 \pm 0.49)$ $\times 10^{21} \mathrm{~N} \mathrm{~m}$ (corresponding to an earthquake of $M_{\mathrm{W}} 7.9$ ) (note that the reason for larger error of the total seismic moment for the IE model than for the HE model comes from the fact that, as seen in Figs. 6(b) and 7(b), errors of afterslips for the IE model are larger than those for the HE model in the southern portion of the afterslip area). Hence, it can be said that the total seismic moment for the IE model is larger than that for the HE model, although the discrepancy between them may be somewhat critical since errors are not small. The difference in the total seismic moment between the IE and HE models is $\sim 33 \%$ when the most probable values are compared. Most of this difference is attributable to the southeastward extreme extension of the U-shaped significant afterslip zone in the southwest corner, which can be seen only in the case of the IE model. The difference also comes from the fact that, as already mentioned, each region forming the U-shaped afterslip zone is slightly thinner in the case of the HE model than that in the case of the IE model. As described in Introduction, the extent of afterslip following an interplate earthquake can play quite a significant role in discussing how much of the cumulative stress built by the plate convergence is compensated for by the co- and postseismic slips, and in discussing the recurrence interval or the size of the next earthquake. Therefore, the larger seismic moment released by afterslip for the IE model than for the HE model may lengthen the recurrence interval or reduce the magnitude of the next earthquake such as the 2003 event in the Hokkaido corner; this can, in turn, influence to a certain extent the assessment of seismic hazard in this region.

In the present study, we do not incorporate other possible factors, that might affect the estimation of the afterslips, such as the viscoelastic relaxation in the upper mantle and poroelastic response in the crust as well as the Earth's curvature; all of these may affect the surface deformation pat- tern to some extent. In future studies, these factors should be also incorporated as much as possible in order to make more reliable estimation of the afterslips.

\section{Conclusions}

In this study, we invert geodetic data of horizontal and vertical surface displacements to estimate the 1-yr afterslip following the 2003 Tokachi-oki earthquake. In inversions, we use the GFs calculated for the inhomogeneous elastic (IE) model incorporating the subsurface structure beneath Hokkaido and Tohoku districts. For comparison, we also perform inversions with the GFs calculated for the homogeneous elastic (HE) model. The displacement data are those obtained at 142 continuous GPS stations in Hokkaido and northernmost Tohoku district and two offshore PG stations far off the Pacific coast of Hokkaido.

The results of the inversions can be summarized as follows:

(1) Based on the GFs calculated for the IE model, the significant afterslip zone shows a U-shaped pattern with an extreme extension of the southwest corner toward the far offshore in the southeast direction. Such a Ushaped distribution pattern is the most striking feature of the significant afterslip zone. The amount of afterslip within 1-yr after the 2003 event reaches up to $0.9 \mathrm{~m}$, and the area with no afterslip encircled by significant afterslip zone corresponds to the area of coseismic rupture.

(2) If the HE model is used, the significant afterslip zone is almost similar to that based on the IE model. However, a remarkable difference can be seen; the extreme extension of the U-shaped significant afterslip zone at the southwest corner recognized in the case of using GFs for the IE model disappears in this case. Besides, each region forming the U-shaped afterslip zone seems to be slightly thinner than that in the case of using GFs for the IE model.

(3) The total seismic moment released by the afterslip estimated with the GFs for the IE model (i.e., (1.06 \pm $0.60) \times 10^{21} \mathrm{~N} \mathrm{~m}$ corresponding to an earthquake of $\left.M_{\mathrm{W}} 8.0\right)$ is larger than that with the GFs for the HE model (i.e., $(0.80 \pm 0.49) \times 10^{21} \mathrm{~N}$ m corresponding to an earthquake of $M_{\mathrm{W}} 7.9$ ) by $\sim 33 \%$ (when the most probable values are compared). Such a discrepancy in the estimated seismic moment released by afterslip can influence the evaluation of the recurrence interval or the size of the next earthquake of 2003 event type in the Hokkaido corner.

Based on these results, we may conclude that the afterslip following the 2003 Tokachi-oki earthquake inverted with the GFs for the IE model incorporating the subsurface structure is different to a considerable extent from that with the GFs for the HE model. This suggests that, in geodetic inversions, the GFs calculated for the IE model considering the subsurface structure should be used like in the present study instead of those for the HE model. 
Acknowledgments. The GFs used in this study were calculated with GeoFEM, a parallelized finite element code developed at the Research Organization for Information Science and Technology (RIST), on the Earth Simulator (ES) at the Earth Simulator Center of Japan Agency for Marine-Earth Science and Technology (JAMSTEC). The 3D finite element grid used for the calculations of GFs was originally created by Mr. Naoya Minagawa when he was student at the Graduate School of Education, Tokyo Gakugei University, with the CHIKAKU system consisting of the CHIKAKU-DB, CHIKAKU-CAD and CHIKAKU-MESH developed at the RIKEN and the Japan Atomic Energy Agency (JAEA). We also thank Prof. Kazuro Hirahara at Kyoto University for his kind help and advice in the calculations of GFs with GeoFEM on ES. Comments from Dr. Miura of Tohoku University and an anonymous reviewer were quite useful to improve the manuscript. Most of the figures in this paper were generated with the Generic Mapping Tools (Wessel and Smith, 1998).

\section{References}

Akaike, H., Likelihood and the Bayes procedure, in Bayesian Statistics, edited by J. M. Berbardo, M. H. DeGroot, D. V. Lindley, and A. F. M. Smith, pp. 143-166, Univ. Press, Valencia, 1980.

Baba, T., K. Hirata, T. Hori, and H. Sakaguchi, Offshore geodetic data conductive to the estimation of the afterslip distribution following the 2003 Tokachi-oki earthquake, Earth Planet. Sci. Lett., 241, 281-292, 2006

Bürgmann, R., M. Kogan, V. Levin, C. Scholz, R. King, and G. Steblov, Rapid aseismic moment release following the 5 December, 1997, Kronotsky, Kamchatka earthquake, Geophys. Res. Lett., 28, 1331-1334, 2001 .

Comninou, M. and J. Dundurs, The angular dislocation in a half space, $J$. Elasticity, 5, 203-216, 1975.

Dambara, T. and Y. Tomoda, Geodesy and Geophysics, 286pp, Kyoritsushuppan, Tokyo, 1969 (in Japanese).

Hagiwara, Y., Effects of the Pacific and Philippine-Sea plates on the gravity field in central Japan, J. Geod. Soc. Jpn., 32, 12-22, 1986 (in Japanese with English abstract).

Hasegawa, A., N. Umino, A. Takagi, S. Suzuki, Y. Motoya, S. Kameya, K. Tanaka, and Y. Sawada, Spatial distribution of earthquakes beneath Hokkaido and Northern Honshu, Japan, Zisin (J. Seismol. Soc. Jpn.), 36, 129-150, 1983 (in Japanese with English abstract).

Heki, K., S. Miyazaki, and H. Tsuji, Silent fault slip following an interplate thrust earthquake at the Japan trench, Nature, 386, 595-598, 1997.

Hirata, K., M. Aoyagi, H. Mikada, K. Kawaguchi, Y. Kaiho, R. Iwase, S. Morita, I. Fujisawa, H. Sugioka, K. Mitsuzawa, K. Suyehiro, H. Kinoshita, and N. Fujiwara, Real-time geophysical measurements on the deep seafloor using submarine cable in the southern Kurile subduction zone, IEEE J. Oceanic Eng., 27, 170-181, 2002.

Hirose, H., K. Hirahara, F. Kimata, N. Fujii, and S. Miyazaki, A slow thrust slip event following the two 1996 Hyuganada earthquakes beneath the Bungo Channel, southwest Japan, Geophys. Res. Lett., 26, 3237-3240, 1999.

Hyodo, M. and K. Hirahara, GeoFEM kinematic earthquake cycle simulation in southwest Japan, Pure Appl. Geophys., 161, 2069-2090, 2004.

Iizuka, M., D. Sekita, H. Suito, M. Hyodo, K. Hirahara, D. Place, P. Mora, O. Hazama, and H. Okuda, Parallel simulation system for earthquake generation: fault analysis modules and parallel coupling analysis, Concurrency Computat.: Pract. Exper., 14, 499-519, 2002.

Kanai, T., A. Makinouchi, and A. Nakagawa, Tectonic CAD system and the construction of 3D solid models of tectonic structures, 1999 Jpn. Earth Planet. Sci. Joint Meeting, Dg-021, 1999 (in Japanese).

Kanai, T., A. Makinouchi, and Y. Oishi, Development of tectonic CAD/database systems, Int. Workshop on Solid Earth Simulation and ACES WG Meeting, 2000.

Kanai, T., Y. Oishi, A. Makinouchi, T. Homma, and T. Miyamura, CHIKAKU modeling system-Tectonic database/CAD software for predictions of earthquake generation and wave propagation-, Seismol. Soc. Jpn. 2005 Fall Meeting, P099, 2001 (in Japanese).

Katsumata, K., N. Wada, and M. Kasahara, Newly imaged shape of the deep seismic zone within the subducting Pacific plate beneath the Hokkaido corner, Japan-Kurile arc-arc junction, J. Geophys. Res., 108, 2565, doi:10.1029/2002JB002175, 2003.

Lawson, C. L. and R. J. Hanson, Solving Least Squares Problems, PrenticeHall Series in Automatic Computation, 340 pp., 1974.
Liu, H.-P., The structure of the Kurile trench-Hokkaido rise system computed by an elastic time-dependent plastic plate model incorporating rock deformation data, J. Geophys. Res., 85, 901-912, 1980.

Miura, S., Y. Suwa, A. Hasegawa, and T. Nishimura, The 2003 M8.0 Tokachi-Oki earthquake-How much has the great event paid back slip debts?, Geophys. Res. Lett., 31, doi:10.1029/2003GL019021, 2004.

Miyamachi, H., M. Kasahara, S. Suzuki, K. Tanaka, and A. Hasegawa, Seismic velocity structure in the crust and upper mantle beneath northern Japan, J. Phys. Earth, 42, 269-301, 1994.

Miyamura, T., T. Kanai, Y. Oishi, K. Hirahara, T. Hori, M. Hyodo, A. Higashida, T. Hirayama, N. Kato, and A. Makinouchi, Mesh generation of crust structures of southwest Japan by using CHIKAKU system, Proc. Computat. Eng. Conf. of Jpn. Soc. Computat. Eng. Sci., 9, 521524, 2004 (in Japanese with English abstract).

Miyazaki, S., T. Sato, M. Sasaki, Y. Hatanaka, and Y. Iimura, Expansion of GSI's GPS array, Bull. Geogr. Surv. Inst., 43, 23-36, 1997.

Miyazaki, S., P. Segall, J. Fukuda, and T. Kato, Space time distribution of afterslip following the 2003 Tokachi-oki earthquake: Implications for variations in fault zone frictional properties, Geophys. Res. Lett., 31 , doi:10.1029/2003GL019410, 2004.

Nakajima, J., T. Matsuzawa, A. Hasegawa, and D. Zhao, Seismic imaging of arc magma and fluids under the central part of northeast Japan, Tectonophysics, 341, 1-17, 2001.

Nishimura, T., S. Miura, K. Tachibana, K. Hashimoto, T. Sato, S. Hori, E. Murakami, T. Kono, K. Nida, M. Mishina, T. Hirasawa, and S. Miyazaki, Distribution of seismic coupling on the subducting plate boundary in northeastern Japan inferred from GPS observations, Tectonophysics, 323, 217-238, 2000.

Nishimura, T., T. Hirasawa, S. Miyazaki, T. Sagiya, T. Tada, S. Miura, and K. Tanaka, Temporal change of interplate coupling in northern Japan during 1995-2002 estimated from continuous GPS observations, Geophys. J. Int., 157, 901-916, doi:10.1111/j.1365-246X.2004.02159.x., 2004

Oishi, Y., T. Miyamura, T. Kanai, K. Hirahara, T. Hori, and M. Hyodo, Hexahedral mesh generation of crust structure of south west Japan, 2004 Japan Earth and Planet. Sci. Joint Meeting, S044-P008, 2004 (in Japanese).

Ozawa, S., M. Kaidzu, M. Murakami, T. Imakiire, and Y. Hatanaka, Coseismic and postseismic crustal deformation after the Mw 8 Tokachi-oki earthquake in Japan, Earth Planets Space, 56, 675-680, 2004.

Sato, K., N. Minagawa, M. Hyodo, T. Baba, T. Hori, and Y. Kaneda, Effect of elastic inhomogeneity on the surface displacements in the northeastern Japan: Based on three-dimensional numerical modeling, Earth Planets Space, 59, 1083-1093, 2007.

Suito, H. and K. Hirahara, Simulation of post-seismic deformations caused by the 1896 Riku-u earthquake, northeast Japan: Re-evaluation of the viscosity in the upper mantle, Geophys. Res. Lett., 26, 2561-2564, 1999.

Suzuki, S., T. Sasatani, and Y. Motoya, Double seismic zone beneath the middle of Hokkaido, Japan, in the southwestern side of the Kurile arc, Tectonophysics, 96, 59-76, 1983.

Tichelaar, B. W. and L. J. Ruff, How good are our best model? Jackknifing and bootstrapping, and earthquake depth, Eos Trans., 70, 593, 605-606, 1989.

Wessel, P. and W. H. F. Smith, New, improved version of generic mapping tools released, Eos Trans., 79, 579, 1998.

Yabuki, T. and M. Matsu'ura, Geodetic data inversion using a Bayesian information criterion for spatial distribution of fault slip, Geophys. $J$. Int., 109, 363-375, 1992.

Yagi, Y., Source rupture process of the 2003 Tokachi-oki earthquake determined by joint inversion of teleseismic body wave and strong ground motion data, Earth Planets Space, 56, 311-316, 2004.

Yagi, Y., M. Kikuchi, and T. Sagiya, Co-seismic slip, post-seismic slip, and aftershocks associated with two large earthquakes in 1996 in Hyuganada, Japan, Earth Planets Space, 53, 793-803, 2001.

Yamanaka, Y. and M. Kikuchi, Source process of the recurrent Tokachioki earthquake on September 26, 2003, inferred from teleseismic body waves, Earth Planets Space, 55, e21-e24, 2003.

Zhao, D., S. Horiuchi, and A. Hasegawa, Seismic velocity structure of the crust beneath the Japan islands, Tectonophysics, 212, 289-301, 1992.

Zhao, D., A. Hasegawa, and H. Kanamori, Deep structure of Japan subduction zone as derived from local, regional and teleseismic events, $J$. Geophys. Res., 99, 22313-22329, 1994.

K. Sato (e-mail: sato@u-gakugei.ac.jp), T. Baba, T. Hori, M. Hyodo, and Y. Kaneda 